\title{
Resultados de la implementación de un protocolo de soporte nutricional en grandes quemados pediátricos internados en la Unidad de Cuidados Intensivos \\ Results of the implementation of a nutritional support protocol for major burn pediatric patients hospitalized in the Intensive Care Unit
}

\author{
Dra. Nidia Tramonti, ${ }^{a}$ Dra. Jimena Lema, ${ }^{a}$ Dra. María B. Araujo, ${ }^{b}$ Dr. Hugo Basilico, ${ }^{a}$ \\ Dra. Rosa M. Villasboas, ${ }^{a}$ Dr. Santiago Laborde, ${ }^{a}$ Lic. Gabriela D'Isa ${ }^{c} y$ \\ Dra. Carolina Caminitib
}

\section{RESUMEN}

Introducción: "Gran quemado" es quien sufre lesiones por daño térmico que afectan más del $30 \%$ de su superficie corporal (SC). El hipercatabolismo secundario causa pérdida de masa magra y retraso de la cicatrización de heridas.

Objetivo: Describir y analizar los resultados de la implementación de un protocolo de soporte nutricional en niños quemados graves internados en una Unidad de Cuidados Intensivos durante las primeras 6 semanas evolutivas.

Población y métodos: Diseño analítico, prospectivo, observacional y longitudinal. Se midieron peso, talla, porcentaje de SC quemada, días de internación en la Unidad de Cuidados Intensivos y mortalidad. Se analizaron tasa metabólica basal por calorimetría indirecta y fórmula de Schofield, cobertura de aporte energético y proteico, prealbúmina, proteína $C$ reactiva, vitaminas $A, D, E$, cobre y zinc semanales.

Resultados: Se incluyeron 18 pacientes (media: 3,9 años, 49\% de SC quemada). Se alcanzó la media de objetivo energético en la segunda semana y el requerimiento proteico en la semana 6. Doce pacientes requirieron nutrición parenteral complementaria sin complicaciones. Se hallaron parámetros de hipermetabolismo, que senormalizaron a las 4-6 semanas delingreso, excepto la proteína $C$ reactiva. Las vitaminas A y E y elementos traza (zinc y cobre) estaban descendidos al ingreso con mejoría posterior. La vitamina $\mathrm{D}$ persistió en valores bajos. Un paciente falleció.

Conclusiones: La implementación del protocolo permitió lograr el aporte de la totalidad del requerimiento energético; la cobertura del requerimiento proteico se postergó hasta la semana 6. Es necesario hacer hincapié en resolver las limitaciones para alcanzar este último.

Palabras clave: unidades de quemados, apoyo nutricional, micronutrientes, balance nitrogenado, metabolismo basal.

Conflicto de intereses:

Ninguno que declarar.

Recibido: 2-8-2017

Aceptado: 23-1-2018 http:/ / dx.doi.org/10.5546/aap.2018.e515

Texto completo en inglés:

http:/ / dx.doi.org/10.5546/aap.2018.eng.e515
Cómo citar: Tramonti N, Lema J, Araujo MB, et al. Resultados de la implementación de un protocolo de soporte nutricional en grandes quemados pediátricos internados en la Unidad de Cuidados Intensivos. Arch Argent Pediatr 2018;116(4):e515-e521.

\section{GLOSARIO}

ANOVA: análisis de la varianza.

$\mathrm{BN}$ : balance nitrogenado.

CI: calorimetría indirecta.

CMIA: inmunoensayo de micropartículas quimioluminiscente. $\mathrm{CO}_{2}$ : dióxido de carbono.

GAP: guía de práctica clínica.

HPLC: cromatografía líquida de alta presión.

IMC: índice de masa corporal.

NP: nutrición parenteral.

NUU: nitrógeno ureico urinario.

$\mathrm{O}_{2}$ : oxígeno.

PCR: proteína $C$ reactiva.

Sistema GRADE: clasificación de.

los niveles de evidencia y grados.

de recomendación.

SNG: sonda nasogástrica.

SZ: puntaje Z.

TMB: tasa metabólica basal.

UCI: Unidad de Cuidados Intensivos VR: valor de referencia.

\% SCQ: porcentaje de

superficie corporal quemada.

\section{INTRODUCCIÓN}

Se ha definido como paciente "gran quemado" a aquel que sufre lesiones por daño térmico que afectan más del $30 \%$ de su superficie corporal (SC). ${ }^{1}$ 
Requieren soluciones nutricionales únicas, ya que las consecuencias metabólicas son profundas y constituyen un desafío constante. La extensión de la quemadura afecta directamente la rehidratación, el soporte nutricional y las intervenciones.

El hipermetabolismo secundario a la secreción de hormonas contrarreguladoras (adrenalina, cortisol y glucagón) determina el músculo esquelético como el principal combustible obligatorio, mientras que la capacidad de utilizar la grasa como fuente de energía está reducida, ${ }^{2}$ lo que causa una gran pérdida de masa magra corporal en pocas semanas tras la lesión. El retraso en la escarectomía, la cobertura tanto transitoria como definitiva de las heridas y la sepsis contribuyen también a la lisis del músculo esquelético ${ }^{3}$ debido al incremento aún mayor de la tasa metabólica basal. ${ }^{4}$

Este gran despliegue metabólico se inicia inmediatamente luego de la quemadura. La fase aguda ocurre hasta las primeras 8-12 semanas de producida la lesión ${ }^{5}$ y causa, además de pérdida de masa magra, desmineralización ósea, debilidad muscular y retraso de la cicatrización de las heridas. Este proceso empeora ante la insuficiencia del aporte de energía y proteínas, lo que puede sobrevenir en susceptibilidad a infecciones, disfunción orgánica y, finalmente, la muerte.

Además, los micronutrientes desarrollan un rol fundamental en la inmunidad, síntesis proteica y actividad antioxidante. Se produce la depleción de sus depósitos por el aumento de la producción de radicales libres y peroxidación lipídica, pérdida a través de heridas, orina, drenajes, diarrea ${ }^{6}$ y sistemas de aspiración. ${ }^{7}$ La dificultad en su evaluación incluye la respuesta de fase aguda con disminución de las proteínas transportadoras y la redistribución de los micronutrientes. Asimismo, no hay consenso en la dosis y vía de suplementación debido a la interacción en su absorción por vía enteral, así como la posible intoxicación ante la administración de altas dosis en forma sostenida. ${ }^{6}$

Por todo lo expuesto, proporcionar un soporte nutricional intensivo es un componente esencial en el tratamiento de estos pacientes, ya que reduce la mortalidad. ${ }^{2}$

Con el objetivo de optimizar el apoyo de la nutrición, se desarrolló un protocolo de soporte nutricional basado en la revisión bibliografía no sistemática bajo el sistema GRADE publicado posteriormente como guía de práctica clínica
(GAP 2016) del Hospital de Pediatría Garrahan. ${ }^{8}$

El objetivo del presente trabajo fue describir y analizar los resultados de un protocolo de soporte nutricional que fue implementado en pacientes con quemaduras mayores del $30 \%$ de la SC internados en la Unidad de Cuidados Intensivos (UCI) durante las primeras 6 semanas del ingreso.

\section{POBLACIÓN Y MÉTODOS}

Diseño analítico, prospectivo, observacional y longitudinal. Se incluyeron por muestreo consecutivo todos los niños y adolescentes de ambos sexos menores de 16 años con quemaduras mayores del 30\% de la SC que ingresaron a la UCI Quemados del Hospital Garrahan entre octubre de 2014 y agosto de 2015. En todos los casos, se firmó el consentimiento informado por el padre o los tutores. El trabajo fue avalado por el Comité de Ética de Investigación del Hospital.

En todos los pacientes, se aplicaron los criterios del protocolo de soporte nutricional desarrollado según el siguiente algoritmo.

Descripción breve del protocolo: Se define inicialmente el objetivo de energía (calorimetría indirecta o fórmula de Schofield $+30 \%$ ), así como el objetivo de aporte proteico $(3 \mathrm{~g} / \mathrm{kg} /$ día en niños y 1,5-2 g/ kg/día en adolescentes), que será alcanzado prioritariamente por vía enteral. Luego de la estabilización hemodinámica, en las 24-48 h del ingreso, se inicia la alimentación enteral (sonda nasogástrica -SNG- excepto contraindicaciones (íleo y / o alteración de la perfusión intestinal) en modo de gastroclisis continua con fórmula deslactosada con relación calorías no proteicas/nitrógeno, idealmente, 100:1. Se progresa a la fórmula según el algoritmo específico. $\mathrm{Si}$, a las 72 horas del inicio del aporte, no se logra el objetivo del volumen previsto (70\%), luego de intentar resolver las limitaciones (ej.: sonda transpilórica que rota a fórmula hidrolizada), se iniciará la nutrición parenteral (NP) complementaria. La NP se inicia sin lípidos, con flujo máximo de glucosa de $5-7 \mathrm{mg} / \mathrm{kg} / \mathrm{min}$ y aminoácidos a razón de $30 \mathrm{~g} / \mathrm{L}$. Si la NP es exclusiva, a los 7 días, se deben agregar lípidos a razón de $0,5 \mathrm{~g} / \mathrm{kg} /$ día y aumentar a las $24 \mathrm{~h}$ a $1 \mathrm{~g} / \mathrm{kg} /$ día si los triglicéridos son $<250 \mathrm{mg} / \mathrm{dl}$. Se debe reevaluar la tolerancia enteral diariamente y disminuir la NP a medida que se progresa con la alimentación enteral.

Los requerimientos de los micronutrientes (vitaminas A, E y D, elementos traza zinc y cobre) se cubren tanto con la suplementación enteral con polivitamínicos como con la NP. Su aporte 
se triplica en promedio, al sumar lo que aporta la fórmula para alimentación enteral.

\section{Variables de estudio}

Se midió al ingreso el peso en una camabalanza y la talla en decúbito dorsal con un pediómetro. Se calculó el índice de masa corporal (IMC) y sus respectivos puntajes Z (SZ). Se registró sexo, edad, porcentaje de $S C$ quemada (\%SCQ), etiología y días de internación en la UCI.

La tasa metabólica basal (TMB) (energía requerida para mantener el funcionamiento fisiológico basal normal) se observó mediante calorimetría indirecta (CI) usando un analizador de intercambio de gas con medición del consumo de oxígeno $\left(\mathrm{O}_{2}\right)$ y producción de dióxido de carbono $\left(\mathrm{CO}_{2}\right)$ (CCM Express de MEDGRAPHICS) durante 20 minutos. En los pacientes en los que no pudo realizarse dicho procedimiento, se estimó con la fórmula de Schofield. ${ }^{8,9}$

El aporte energético se indicó según la $\mathrm{TMB}+30 \%$ para evitar la subestimación del requerimiento.

Se recabó el promedio semanal de aporte enteral y parenteral del registro de enfermería, con lo que se calculó el aporte energético (calorías $/ \mathrm{kg}$ ) y proteico (gramos de proteínas $/ \mathrm{kg}$ ). Se realizó el balance energético y nitrogenado $(\mathrm{BN})$ hasta el inicio de la alimentación por vía oral.

Se midió la urea-urinaria de $24 \mathrm{~h}$ por test cinético con ureasa y glutamato deshidrogenasa (valor de referencia -VR-12-20 g/24 h) y se calculó el BN según la siguiente fórmula:

$\mathrm{BN}=$ aportado - nitrógeno $(\mathrm{N})$ urinario $\mathrm{N}$ fecal / piel - $\mathrm{N}$ eliminado por quemadura

$\mathrm{N}$ aportado: proteínas aportadas en $\mathrm{g} / 6,25$. $\mathrm{N}$ urinario: (urea urinaria de $24 \mathrm{~h} / 2,1$ ) $+20 \%$. $\mathrm{N}$ fecal/piel: $2 \mathrm{~g}$ / día en $<4$ años, $3 \mathrm{~g} /$ día entre 4 y 10 años y $4 \mathrm{~g} /$ día en $>10$ años. $N$ eliminado por quemadura: $0,12 \mathrm{~g} / \mathrm{kg} /$ día.

Se llevaron a cabo las siguientes determinaciones de laboratorio: prealbúmina y proteína $C$ reactiva (PCR), ambas por método inmunoturbidimétrico automatizado (VR: 20$40 \mathrm{mg} / \mathrm{dl} \mathrm{y}<5 \mathrm{mg} / \mathrm{L}$, respectivamente), vitamina A y E por cromatografía líquida de alta presión (HPLC por sus siglas en inglés) (VR: 20-50 mcg/ dl y desde $600 \mathrm{mcg} / \mathrm{dl}$, respectivamente). Elementos traza: cobre y zinc por espectrofotometría de absorción atómica (VR: 66-166 mcg/dl y 50$120 \mathrm{mcg} / \mathrm{dl}$, respectivamente) y vitamina D por inmunoensayo de micropartículas quimioluminiscente (chemiluminescent microparticle immuno assay; CMIA, por sus siglas en inglés) (VR $>30 \mathrm{ng} / \mathrm{ml})$.

Todas las mediciones se realzaron durante las semanas 1, 2, 3, 4 y 6 desde el ingreso.

\section{Variables de resultado}

Se evaluó el tiempo de inicio de la alimentación enteral, la cobertura del aporte energético y proteico semanal, y la mortalidad.

Se consideró como cobertura aceptable haber alcanzado el $70 \%$ del objetivo energético y proteico.

\section{Análisis estadístico}

Se realizó un análisis descriptivo y analítico. Se analizó el comportamiento de cada variable y, según su distribución, se informó en normales, media y desvíos estándar, y en sesgadas, mediana y rango. Las variables normales se analizaron con el test de Student y las sesgadas, con el Wilcoxon Rank Test. Las variables categóricas se analizaron con $\mathrm{chi}^{2} /$ Fisher. Se realizó el test de análisis de la varianza (analysis of variance; ANOVA, por sus siglas en inglés) para identificar las diferencias entre las mediciones seriadas de la misma variable. Se asumieron test a dos colas y con significación estadística $\mathrm{p}<0,05$. Se utilizó el paquete estadístico STATA versión 10.

\section{RESULTADOS}

Se reclutaron 18 pacientes que cumplieron los criterios de inclusión. En la Tabla 1, se observan los datos demográficos. La mediana de edad fue de 3,9 años $(0,2-14,9)$. Doce pacientes eran varones. Desde el punto de vista antropométrico, todos los pacientes presentaron un estado nutricional normal al ingreso según el SZ-IMC. El \%SCQ fue del 49\% (34-87\%); el 55\% de los pacientes sufrió la quemadura por fuego directo. Doce pacientes $(66 \%)$ iniciaron la alimentación enteral antes de las $48 \mathrm{~h}$ del ingreso. La mediana de internación en la UCI fue de 45 días (10-144).

Tabla 1. Datos demográficos $(n=18)$

\begin{tabular}{lc}
\hline Variable & Media \pm DE/mediana (rango) \\
\hline Edad (años) & $3,9(0,2-14,9)$ \\
SZ-peso & $0,7($ de $-0,6$ a 2,3) \\
SZ-talla & $1,1($ de $-1,2$ a 2,4$)$ \\
SZ-IMC & $19,2( \pm 2,2)$ \\
Superficie corporal quemada (\%) & $49(34-87 \%)$ \\
Días de internación en la UCI (días) & $45(10-144)$ \\
\hline
\end{tabular}

SZ: puntaje Z; IMC: índice de masa corporal;

UCI: Unidad de Cuidados Intensivos; DE: desvío estándar. 
El requerimiento energético y el aporte enteral y parenteral se observan en la Tabla 2. Debido a que el aporte enteral se analizó hasta el inicio de la vía oral, se redujo el número de pacientes analizados en forma semanal de la siguiente manera: en la semana $1,100 \%(18 / 18)$; en la semana $2,94 \%$ (17/18); en la semana $3,83 \%$ $(15 / 18)$; en la semana $4,72 \%(13 / 18) \mathrm{y}$, en la semana $6,61 \%(11 / 18)$.

El aporte energético y proteico total recibido se incrementó semanalmente en forma significativa (ANOVA p 0,03). Como se observa en la Tabla 2, se alcanzó la media de cobertura del requerimiento energético a partir de la segunda semana del ingreso, mientras que la media del objetivo proteico fue alcanzada recién en la sexta semana.
El 67\% (12/18) de los pacientes requirió NP complementaria en algún período de la internación.

En el Figura 1, se observa que $6 / 18$ pacientes alcanzaron el objetivo energético aceptable durante la primera semana. Mientras que todos los pacientes lo hicieron a partir de la segunda semana del ingreso.

Con respecto al aporte proteico, $10 / 18$ pacientes alcanzaron el aporte aceptable en la segunda semana, que se incrementó semanalmente. Analizada como variable continua, en la sexta semana, se cubrió la media del requerimiento proteico.

La media de prealbúmina de la población estuvo disminuida al ingreso $(6,9 \pm 3,2)$, con aumento en forma estadísticamente significativa

TABLA 2. El requerimiento energético y el aporte enteral y parenteral (n inicial=18)

\begin{tabular}{lcccccccc}
\hline & $\begin{array}{c}\text { Energía } \\
\text { enteral } \\
\text { recibida } \\
\text { (cal/kg/día) }\end{array}$ & $\begin{array}{c}\text { Proteínas } \\
\text { enterales } \\
\text { recibidas } \\
\text { (g/kg/día) }\end{array}$ & $\begin{array}{c}\text { Energía } \\
\text { por NP } \\
\text { recibida } \\
\text { (cal/kg/día) }\end{array}$ & $\begin{array}{c}\text { Proteínas } \\
\text { por NP } \\
\text { recibida } \\
\text { (g/kg/día) }\end{array}$ & $\begin{array}{c}\text { Energía } \\
\text { total } \\
\text { recibida } \\
\text { (cal/kg/día) }\end{array}$ & $\begin{array}{c}\text { Proteínas } \\
\text { totales } \\
\text { recibidas } \\
\text { (g/kg/día) }\end{array}$ & $\begin{array}{c}\% \text { del } \\
\text { objetivo } \\
\text { energético } \\
\text { recibido }\end{array}$ & $\begin{array}{c}\% \text { del } \\
\text { objetivo } \\
\text { proteico } \\
\text { recibido }\end{array}$ \\
\hline Semana 1 & 28 & 0,8 & 16,5 & 1,3 & 31 & 1,2 & 61 & 60 \\
$\mathrm{~N}=18$ & $(8,8-93)$ & $(0,3-2,7)$ & $(5,8-32,6)$ & $(0,3-2)$ & $(13,5-93)$ & $(0,45-4)$ & $(26-138)$ & $(15-106)$ \\
Semana 2 & 59 & 1,8 & 12 & 1,5 & 59 & 2,1 & 115 & 73 \\
$\mathrm{~N}=17$ & $(22-98)$ & $(0,8-2,9)$ & $(5,4-32)$ & $(0,4-2)$ & $(22-98)$ & $(1,2-3,9)$ & $(76-182)$ & $(17-140)$ \\
Semana 3 & 54 & 1,3 & 18,5 & 1,2 & 58 & 2,2 & 121 & 93 \\
$\mathrm{~N}=15$ & $(26-96)$ & $(0,7-2,8)$ & $(8,3-25)$ & $(0,7-1,9)$ & $(27-96,7)$ & $(1,5-3,8)$ & $(72-172)$ & $(35-126)$ \\
Semana 4 & 44 & 1,4 & 19 & 1,3 & 53 & 2,1 & 109 & 94 \\
$\mathrm{~N}=13$ & $(10-79)$ & $(0,3-2,5)$ & $(10-42)$ & $(0,9-2,2)$ & $(13,5-95)$ & $(1,6-3,8)$ & $(75-170)$ & $(60-126)$ \\
Semana 6 & 54 & 1,8 & 17,8 & 1,3 & 80 & 3,2 & 139 & 110 \\
$\mathrm{~N}=11$ & $(35-102)$ & $(1-3,5)$ & $(8-45)$ & $(0,7-2,2)$ & $(35-102)$ & $(1-4)$ & $(110-166)$ & $(50-133)$ \\
\hline
\end{tabular}

NP: nutrición parenteral.

FIgURA 1. Porcentaje de pacientes que alcanzaron el aporte del $70 \%$ del objetivo energético y proteico

Cobertura proteica $>\mathbf{7 0} \%$ Cobertura energética $>70 \%$

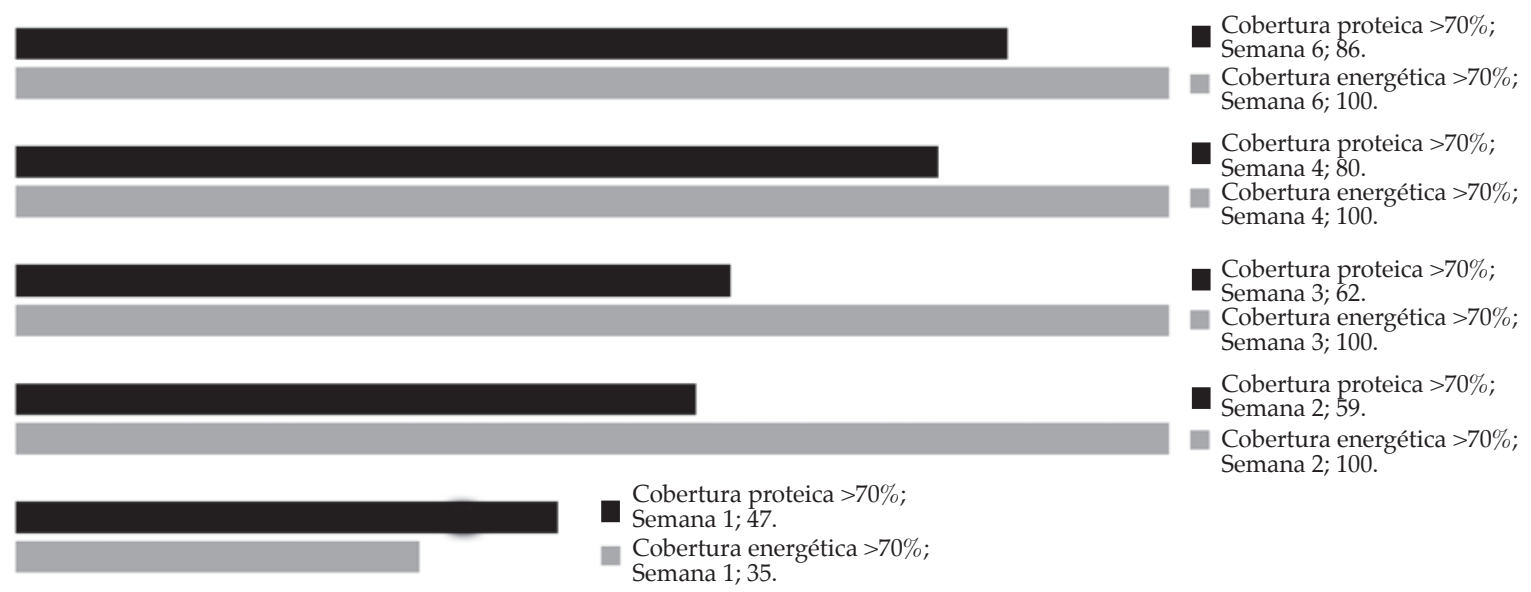


hacia las semanas 3, 4 y 6 ( $p<0,01)$; en cambio, los valores de PCR se mantuvieron elevados. El nitrógeno ureico urinario (NUU) se incrementó hasta la semana 3 desde el ingreso $(8,2 \pm 3,8$ vs. $13,1 \pm 3,8 ; \mathrm{p} 0,03)$ y descendió luego en forma estadísticamente significativa. Asimismo, el BN varió de modo significativo: fue negativo al inicio y se positivizó hacia la semana 6 (Tabla 3 ).

En la Tabla 4, se muestran las determinaciones semanales de micronutrientes y el porcentaje de pacientes con dosajes en rango normal. Las vitaminas A y E se encontraron disminuidas al ingreso con incremento posterior (ANOVA $p<0,01)$. La vitamina A se normalizó en todos los pacientes en la semana 6, mientras que la E lo hizo en la tercera semana de internación. No hubo diferencias estadísticamente significativas entre los dosajes de cobre y zinc al ingreso con respecto a las determinaciones siguientes; sin embargo, se normalizaron en el $60 \%$ de la población estudiada a las 6 semanas. Inversamente, la vitamina D persistió en valores descendidos durante el estudio.

No se encontraron diferencias significativas en el dosaje de micronutrientes en pacientes que hubieran recibido NP complementaria o no.

Un paciente falleció por falla multiorgánica secundaria a sepsis.

\section{DISCUSIÓN}

Se enfatiza la importancia de la utilización de un protocolo de soporte nutricional en pacientes quemados críticos. Existe vasta evidencia bibliográfica a favor de su utilización para aumentar el éxito del soporte nutricional. ${ }^{2}$ Hamilton y col. ${ }^{10}$ encontraron un descenso significativo de las interrupciones en la alimentación enteral y en el tiempo para alcanzar el requerimiento energético al implementar un protocolo a tal fin.

El aporte energético total se incrementó semanalmente en forma significativa y alcanzó la cobertura de la media del requerimiento energético a partir de la segunda semana del ingreso, mientras que la media del objetivo proteico fue alcanzada recién en la semana 6 . Se interpreta que el retraso en el alcance del aporte proteico pudo deberse a limitaciones clínicas, como inestabilidad hemodinámica, insuficiencia renal aguda, entre otras, y la utilización de fórmulas enterales, que, a pesar de tener menor relación calorías no proteicas/nitrógeno comparadas con las fórmulas para niños no críticos, continúan siendo menos efectivas para alcanzar el aporte proteico en pacientes con alto requerimiento. Se utilizó la NP complementaria al existir limitaciones que impidieran lograr

TABLA 3. Dosaje de prealbúmina, proteína C reactiva, nitrógeno ureico urinario de 24 h y balance nitrogenado $(n=18)$

\begin{tabular}{lccccc}
\hline & Semana 1 & Semana 2 & Semana 3 & Semana 4 & Semana 6 \\
\hline Prealbúmina (mg/dl) & $6,9 \pm 3,2$ & $9,5 \pm 4,7$ & $13,8 \pm 7,8 \#$ & $11,3 \pm 5,6^{*}$ & $18,4 \pm 8 \#$ \\
PCR (mg/L) & $143 \pm 105$ & $125 \pm 90$ & $143 \pm 126$ & $185 \pm 139$ & $135 \pm 161$ \\
Nitrógeno ureico urinario, 24 h (g/día) & $8,2 \pm 3,8$ & $9,6 \pm 5,3$ & $13,1 \pm 3,8 \#$ & $7,9 \pm 3,4^{*}$ & $7,8 \pm 5,5^{*}$ \\
Balance nitrogenado (g/día) & $-2,3 \pm 4,7$ & $-0,7 \pm 4,5$ & $1,3 \pm 2,9$ & $-0,4 \pm 1$ & $2 \pm 2 \#$ \\
\hline
\end{tabular}

PCR: proteína $C$ reactiva.

${ }^{*} \mathrm{p}<0,01$ comparada con la semana 1 .

$\# \mathrm{p}<0,005$ comparada con la semana 1 .

TABla 4. Determinaciones plasmáticas de vitaminas $A, E, D$ y elementos traza zinc y cobre y porcentaje de determinaciones de micronutrientes dentro del rango normal $(n=18)$

\begin{tabular}{|c|c|c|c|c|c|c|c|c|c|c|}
\hline \multirow[b]{2}{*}{$\begin{array}{l}\text { Vitamina A } \\
20-50 \mathrm{mcg} / \mathrm{dl}\end{array}$} & \multicolumn{2}{|c|}{ Semana 1} & \multicolumn{2}{|c|}{ Semana 2} & \multicolumn{2}{|c|}{ Semana 3} & \multicolumn{2}{|c|}{ Semana 4} & \multicolumn{2}{|c|}{ Semana 6} \\
\hline & $\begin{array}{c}18 \\
(10-40)\end{array}$ & $22 \%$ & $\begin{array}{c}21 \\
(15-34)\end{array}$ & $55 \%$ & $\begin{array}{c}22,5 \\
(9-63)\end{array}$ & $62 \%$ & $\begin{array}{c}37 \\
(17-45)\end{array}$ & $80 \%$ & $\begin{array}{c}53 \\
(35-100)^{*}\end{array}$ & $100 \%$ \\
\hline $\begin{array}{l}\text { Vitamina E } \\
>600 \mathrm{mcg} / \mathrm{dl}\end{array}$ & $\begin{array}{c}537 \\
(403-1832)\end{array}$ & $44 \%$ & $\begin{array}{c}837 \\
(432-1271)\end{array}$ & $77 \%$ & $\begin{array}{c}1339 \\
(912-2016)^{*}\end{array}$ & $100 \%$ & $\begin{array}{c}1421 \\
(898-2334)^{*}\end{array}$ & $100 \%$ & $\begin{array}{c}1432 \\
(938-2207)^{*}\end{array}$ & $100 \%$ \\
\hline $\begin{array}{l}\text { Vitamina D } \\
>30 \mathrm{ng} / \mathrm{ml}\end{array}$ & $\begin{array}{c}10,8 \\
(6,8-26,8)\end{array}$ & $0 \%$ & $\begin{array}{c}13,5 \\
(7,6-23,8)\end{array}$ & $0 \%$ & $\begin{array}{c}13,2 \\
(9-25,9)\end{array}$ & $0 \%$ & $\begin{array}{c}12,3 \\
(9-19)\end{array}$ & $0 \%$ & $\begin{array}{c}17,4 \\
(9-21,7)\end{array}$ & $0 \%$ \\
\hline $\begin{array}{l}\text { Cobre } \\
66-166 \mathrm{mcg} / \mathrm{dl}\end{array}$ & $\begin{array}{c}50 \\
(18,9-63,9)\end{array}$ & $0 \%$ & $\begin{array}{c}40 \\
(22-68)\end{array}$ & $11 \%$ & $\begin{array}{c}35 \\
(30-76)\end{array}$ & $12 \%$ & $\begin{array}{c}52,8 \\
(51-60)\end{array}$ & $33 \%$ & $\begin{array}{c}62 \\
(30-117)\end{array}$ & $63 \%$ \\
\hline $\begin{array}{l}\text { Zinc } \\
50-120 \mathrm{mcg} / \mathrm{dl}\end{array}$ & $\begin{array}{c}51 \\
(22-108)\end{array}$ & $45 \%$ & $\begin{array}{c}44 \\
(29-61)\end{array}$ & $22 \%$ & $\begin{array}{c}39,5 \\
(32-44)\end{array}$ & $5 \%$ & $\begin{array}{c}51,5 \\
(37-54)\end{array}$ & $75 \%$ & $\begin{array}{c}63 \\
(25-110)\end{array}$ & $65 \%$ \\
\hline
\end{tabular}

\footnotetext{
${ }^{*} \mathrm{p}<0,01$ comparada con la semana 1 .
} 
alcanzar el objetivo energético/proteico por vía enteral. ${ }^{11-13}$ En este sentido, el uso juicioso de NP es avalado por expertos en pacientes críticos pediátricos, indicada ante la falla en lograr el aporte adecuado por vía enteral..$^{14,15} \mathrm{Si}$ se supera el requerimiento energético, la sobrealimentación puede llevar al incremento de $\mathrm{CO}_{2^{\prime}}$ hígado graso, aumento de nitrógeno ureico e hiperglucemia. ${ }^{11}$

El incremento del nivel de la prealbúmina en las semanas 3, 4 y 6, en comparación con los valores de la primera semana, fue estadísticamente significativo, sin diferencias en los reactantes de fase aguda (PCR), de modo simultáneo a la positivización del BN. Está ampliamente descrito el aumento del catabolismo proteico con aumento de eliminación de NUU y BN negativo hasta la segunda semana posquemadura extensa.

Diaz, et al. caracterizaron la tasa de síntesis proteica en 87 niños con quemaduras graves durante 24 meses y encontraron que se había mantenido elevada el primer año poslesión. ${ }^{16}$

Con las determinaciones realizadas, se observa el aumento de la síntesis proteica, imprescindible para el cierre de heridas y prendimiento de injertos. Alcanzar los objetivos de aporte energético y proteico permite reducir, aunque no anular, el catabolismo proteico.

Las vitaminas A y E se encontraron disminuidas al ingreso con incremento posterior (ANOVA $\mathrm{p}<0,01)$. La mayoría de los estudios coinciden en que las determinaciones de dichas vitaminas están descendidas a las dos semanas de la quemadura ${ }^{17}$ con descenso diario de alfa-tocoferol, marcador del depósito de vitamina E en el tejido adiposo. ${ }^{18}$ Está descrita la normalización de las determinaciones plasmáticas en adultos a los 21 días de la quemadura, con la suplementación por vía enteral. ${ }^{19}$

En el presente estudio, se observó la vitamina D disminuida desde el ingreso y su persistencia debajo del rango normal. Este hecho coincide con trabajos previos que confirman niveles descendidos de esta vitamina y de su proteína transportadora, y consideran que parte de esta alteración sería por la hipoproteinemia característica de la etapa aguda del paciente gran quemado. Otros autores ${ }^{20}$ constataron, en adultos con antecedente de quemadura $>50 \%$, reducción en la formación ósea y tasa de depósito mineral comparada con controles sanos. El origen de dicha alteración podría ser multifactorial: hipoalbuminemia, citoquinas inflamatorias, corticoides endógenos y exógenos, inmovilización, ingesta inadecuada, además de pérdida por heridas e incapacidad de síntesis de la epidermis. ${ }^{21}$ Asimismo, Klein y col. encontraron persistencia del déficit de vitamina $\mathrm{D}$ en niños con antecedente de quemadura $>40 \%$, incluso hasta 7 años después. ${ }^{22}$

En nuestro trabajo, se observa que los dosajes bajos de cobre y zinc al ingreso se normalizan a las 6 semanas en el $60 \%$ de la población estudiada. Está descrito un descenso de ambos minerales, al igual que de sus proteínas transportadoras (albúmina y ceruloplasmina) y su redistribución desde el músculo y el hueso hacia la herida y otros tejidos. ${ }^{2}$ Estudios realizados en niños con quemaduras $>40 \%$ suplementados por vía enteral con una dosis tres veces superior a la recomendación no encontraron normalización en las determinaciones plasmáticas al egreso hospitalario. ${ }^{23}$ Además, Berger y col. demostraron prospectivamente, en adultos quemados graves, que la suplementación con cobre, zinc y selenio en forma endovenosa había mejorado la cicatrización de las heridas, número de infecciones ${ }^{24} \mathrm{y}$ catabolismo proteico ${ }^{25}$. La dosis y la vía de administración de micronutrientes continúan siendo controvertidas.

Se requieren más estudios enfocados especialmente en la suplementación de micronutrientes, la cicatrización de heridas y la mortalidad.

\section{CONCLUSIONES}

La implementación del protocolo de soporte nutricional permitió que la media del requerimiento energético fuera alcanzada hacia la segunda semana, a pesar de lo cual se postergó hasta la semana 6 la cobertura del requerimiento proteico. Por ello, fue necesaria su optimización mediante el aporte enteral con fórmulas con menor relación calorías no proteicas/ nitrógeno o complemento parenteral.

\section{REFERENCIAS}

1. Parvizi D, Kamolz LP, Giretzlehner M, et al. The potential impact of wrong TBSA estimation on fluid resuscitation in patients suffering from burns: things to keep in mind. Burns 2014;40(2):241-5.

2. Herndon D. Tratamiento integral de las quemaduras. 3 ed. Barcelona: Elsevier Masson; 2009

3. Prelack K, Yu Y, Dylewski M, et al. The Contribution of Muscle to Whole Body Protein Turnover Throughout the Course of Burn Injury in Children. J Burn Care Res 2010;31(6):942-8.

4. Dylewsky, M, Prelack K, Weber J, et al. Malnutrition among pediatric burn patients: A consequence of delayed admissions. Burns 2010;36(8):1185-9.

5. Jeschke M, Chinkes D, Finnerty C, et al. Pathophysiology 
response to severe burn injury. Ann Surg 2008;248(3): 387401.

6. Berger MM. Antioxidants micronutrients in mayor trauma and burns: evidence and practice. Nutr Clin Pract 2006;21(5):438-49.

7. Hourigan LA, Omaye ST, Keen CL, et al. Vitamin and trace element loss from negative-pressure wound therapy. Adv Skin Wound Care 2016;29(1):20-5.

8. CaminitiC, Tramonti N, Murruni A, etal.GAP2016: Manejo Nutricional en Niños Quemados Graves. Hospital Nacional de Pediatría J. P. Garrahan. [Consulta: 26 de enero de 2018]. Disponible en: http:/ / www.garrahan.gov.ar/guias-deatencion-pediatrica/guias-de-atencion-pediatrica/guiasde-atencion-pediatrica.

9. Rousseau AF, Losser MR, Ichai C, et al. ESPEN endorsed recommendations: Nutritional therapy in major burns. Clin Nutr 2013;32(4):497-502.

10. Hamilton S, McAleer D, Ariagno K, et al. A stepwise enteral nutrition algorithm for critically ill children helps achieve nutrient delivery goals. Pediatr Crit Care Med 2014;15(7):583-9.

11. Rodriguez N, Jeschke M, Williams F, et al. Nutrition in burns: Galveston Contributions. JPEN J Parenter Enteral Nutr 2011;35(6):704-14.

12. Dylewsksi M, Baker M, Prelack K, et al. The safety and efficacy of parenteral nutrition among pediatric patients with burn injuries. Pediatr Crit Care Med 2013;14(3):e120-5.

13. Prelack K, Dylewsksi M, Sheridan R. Practical guidelines for nutritional management of burn injury and recovery. Burns 2007;33(1):14-24.

14. Koletzko B, Goulet O, Jochum F, et al. Use of parenteral nutrition in the pediatric ICU: should we panic because of PEPaNIC? Curr Opin Clin Nutr Metab Care 2017;20(3):201-3.

15. Goulet O, Jochum F, Koletzco B. Early or late parenteral nutrition in critically Ill children: practical implications of the PEPaNIC trial. Ann Nutr Metab 2017;70(1):34-8.
16 Diaz EC, Herndon DN, Lee J, et al. Predictors of muscle protein synthesis after severe pediatric burns. J Trauma Acute Care Surg 2015;78(4):816-22.

17. Nguyen TT, Cox CS, Traver DL, et al. Free radical activity and loss of plasma antioxidants, vimtamin E and sulfhydryl groups in patients with burns: the 1993 Moyer Award. J Burn Care Rehabil 1993;14(6):602-9.

18. Traber M, Leonard S, Traber D, et al. Alpha-tocopherol adipose tissue stores are depleted after burn injury in pediatric patients. Am J Clin Nutr 2010;92(6):1378-84.

19. Rock CL, Deschert RE, Khilnani R, et al. Carotenoids and antioxidant vitamins in patients after burn injury. J Burn Care Rehabil 1997;18(3):269-78.

20. Klein G, Herndon D, Rutan T, et al. Bone disease in burn patients. J Bone Miner Res 1993;8(3):337-45.

21. Gottchlich M, Mayes T, Khoury J, et al. Hypovitaminosis D in acutely injured pediatric burn patients. J Am Diet Assoc 2004;104(6):931-41.

22. Klein G, Langman C, Herndon D. Vitamin D depletion following burn injury in children: A possible factor in postburn osteopenia. J Trauma 2002;52(2):346-50.

23. Voruganti S, Klein G, Lu H, et al. Impaired zinc and copper status in children with burn injuries: Need to reassess nutritional requirements. Burns 2005;31(6):711-6.

24. Berger M, Baines M, Raffoul W, et al. Trace element supplementation after major burns modulates antioxidant status and clinical course by way of increased tissue trace element concentrations. Am JClin Nutr 2007;85(5):1293-300.

25. Berger MM, Binnert C, Chiolero RL, et al. Trace element supplementation after major burns increases burned skin trace element concentrations and modulates local protein metabolism but not whole-body substrate metabolism. Am J Clin Nutr 2007;85(5):1301-6. 